\title{
DISTRIBUIÇÃO VERTICAL DO FÓSFORO NO SOLO EM FUNÇÃO DOS MODOS DE APLICAÇÃO
}

\author{
VERTICAL DISTRIBUTION OF PHOSPHORUS IN SOIL IN FUNCTION OF MODES \\ OF APPLICATION
}

\section{Newton Cabral BARBOSA ${ }^{1}$; Everton Martins ARRUDA ${ }^{2}$; Elias BROD ${ }^{3}$; Hamilton Seron PEREIRA ${ }^{4}$}

1. Mestre em Agronomia, Universidade Federal de Goiás - UFG, Jataí, GO, Brasil, cabralagro@ gmail.com; 2. Doutorando em Agronomia, Universidade Federal de Goiás - UFG, Goiânia, GO, Brasil; 3. Engenheiro Agrônomo, Universidade Federal de Goiás - UFG, Jataí, GO, Brasil; 4. Professor, Doutor, Universidade Federal de Uberlândia - UFU, Uberlândia, MG, Brasil.

RESUMO: A demanda de estudos sobre a dinâmica das adubações e uso eficiente de fósforo na agricultura do cerrado brasileiro, foi propósito para este trabalho, cujo objetivo foi verificar a eficiência da combinação de modos de aplicação de fertilizantes fosfatados na distribuição vertical do nutriente no solo. O experimento foi realizado no sudoeste goiano, juntamente com o sistema de produção de soja e milho. O delineamento experimental foi em blocos casualizados, em esquema fatorial 6x6, entre os modos de adubação (100\% da adubação a lanço, $75 \%$ a lanço e $25 \%$ na linha, $50 \%$ a lanço e $50 \%$ na linha, $25 \%$ a lanço e $75 \%$ na linha, $100 \%$ na linha e a testemunha) e as profundidades $0,0-2,5 ; 2,5-5,0 ; 5,0-$ 7,5; 7,5-10,0; 10,0-15,0; 15,0-20,0 cm. Foi utilizado uma dose padrão de $120 \mathrm{Kg}$ ' ha ${ }^{-1}$ de $_{\mathrm{P}_{2}} \mathrm{O}_{5}$ na forma de Fosfato Monoamônico (MAP). As avaliações foram teor de P no solo e foliar, altura e produtividade das plantas de soja, além da altura e produtividade do milho de segunda safra. A associação da adubação em $75 \%$ a lanço e $25 \%$ na linha, mostrou insuficiência para suprir toda necessidade das plantas pelo fósforo. Quando o fertilizante foi aplicado em maior percentual a lanço em área total proporcionou maior acúmulo de fósforo na camada de $0,0-2,5 \mathrm{~cm}$, entretanto, quando houve predomínio da aplicação na linha de plantio os maiores acúmulos ocorreram na camada de 5,0-7,5 $\mathrm{cm}$.

PALAVRAS-CHAVE: Adubação a lanço. Cerrado brasileiro. Glycine max. Linha de plantio. Zea mays.

\section{INTRODUÇÃO}

A região Centro-Oeste possui grande importância econômica em relação a produção de grãos no Brasil, sendo a soja (Glycine max) e o milho (Zea mays) as principais culturas. Os solos do bioma cerrado, por sua vez oxídicos, possuem elevada capacidade de fixação de fósforo $(\mathrm{P})$, e isto, aliado à alta exigência das culturas, por este nutriente, torna o estabelecimento de formas $\mathrm{e}$ fontes de adubação fosfatada uma ferramenta fundamental (MOTOMIYA et al. 2004).

A busca continua por incrementos de produtividade na cultura da soja e do milho tem proporcionado diversas pesquisas relacionadas á eficiência da fertilização com este nutriente $(\mathrm{P})$, tais como seus diferentes métodos de aplicação no solo, fontes e doses empregadas, além do aperfeiçoamento de metodologias analíticas para quantificação deste elemento na solução do solo, dentre outros, sendo várias as formas de investigações que constituem de ferramentas importantes para a nutrição das plantas.

$\mathrm{O}$ fósforo é encontrado em vários processos metabólicos nos vegetais, como na fotossíntese, respiração, transferências de genes e processos que envolvem transferência de energia (STAUFFER; SULEWSKI 2003). Participa da síntese de macromoléculas e da absorção ativa de nutrientes (MARSCHNER, 1995). Apresenta importância destacada devido a sua interação com outros elementos, afetando a sua disponibilidade no solo e para a nutrição vegetal (BLEVINS, 1999).

$\mathrm{O} P$ é o elemento que mais limita a produtividade dos solos do cerrado devido aos baixos teores presentes (SOUSA et al. 2004). Este elemento possui grande capacidade de ser adsorvido as partículas do solo, logo uma aplicação maior de adubos fosfatados faz-se necessária (NOVAIS; SMYTH 1999).

Os modos de aplicação de $\mathrm{P}$ mais utilizados para produção de grãos são a lanço na superfície, com ou sem incorporação; no sulco de semeadura; em covas e em faixas (SOUSA et al. 2004). Dentre essas, uma crescente prática de manejo da adubação fosfatada tem sido realizada em diversas regiões produtoras de grãos no país, trata-se da aplicação do $\mathrm{P}$ a lanço na superfície sem incorporação.

O empresário rural vem aderindo a esta técnica principalmente em razão de um maior rendimento operacional nos campos de produção, de forma que, não exista necessidade de interromper o trabalho da semeadora para abastecer o reservatório de fertilizantes, apenas as caixas de sementes, proporcionado assim uma maior agilidade quando comparado ao sistema convencional em linha de 
plantio. Essa sistematização da produção de grãos tende priorizar as regiões que contemplam possibilidades de uma segunda safra no ano (safrinha), beneficiando a produção pelo menor tempo gasto nas operações de plantio, tanto na primeira como na segunda safra. Segundo Nunes (2011) está forma de manejo de adubação favorece uma maior utilização da água pela cultura antes do final da estação chuvosa.

Esta técnica tem sido bastante utilizada no Brasil, porém são poucos os estudos que relatam sua eficiência em relação a outras técnicas de adubação (SEGATELLI, 2004).

Embora seja relatada uma maior eficiência da aplicação de $\mathrm{P}$ no sulco de plantio quando às doses a serem aplicadas são baixas (FOX; KANG 1978; ANGHINONI; BARBER 1980), as aplicações de $\mathrm{P}$ a lanço podem ser realizadas em casos específicos, ou seja, quando o solo já apresenta teores de $\mathrm{P}$ acima de níveis críticos (RANDALL; HOEFT 1988; BORDOLI; MALLARINO 1998), seja em sistemas de produção em plantio direto, onde conseguimos maiores acúmulos de matéria orgânica no solo e/ou em condições de aplicações sucessivas de fosfatos.

Quando os teores de fósforo estão acima do teor crítico e, portanto, a probabilidade de resposta das culturas é muito baixa ou ausente, obviamente, não se tem observado perda de produtividade com a aplicação superficial (ANGHINONI 1992; PAVINATO; CERETTA 2004). No entanto, quando os teores de fósforo estão abaixo do teor crítico, a produtividade tem sido menor que em áreas onde o fosfato foi aplicado na linha de semeadura (POTTKER 1999).

A intensa preocupação com o uso eficiente dos fertilizantes fosfatados na agricultura moderna deve estar associada ao conhecimento do comportamento do fósforo no solo, mediante suas práticas culturais e formas de manejo, principalmente em solos de extrema deficiência, como é o caso dos solos de cerrado (SOUSA; LOBATO, 2004).

Com isso, o objetivo deste trabalho foi verificar a eficiência da combinação de métodos de aplicação de fertilizantes fosfatados na distribuição vertical do nutriente no solo, em sistemas de produção de grãos.

\section{MATERIAL E MÉTODOS}

$\mathrm{O}$ experimento foi realizado na propriedade rural, no município de Jataí-GO (Latitude $17^{\circ} 83^{\prime} \mathrm{S}$ e longitude $51^{\circ} 63^{\prime} \mathrm{W}$ ), altitude média de 700 metros, precipitação pluvial média anual de 1.800 $\mathrm{mm}$ e o solo sobre o qual foi instalado o experimento foi classificado como Latossolo Vermelho-Amarelo (EMBRAPA, 2006). Cujas principais características físicas e químicas constam na Tabela 1. Anteriormente a área era ocupada com pastagens degradadas e não recebeu nenhuma adubação, este experimento corresponde ao primeiro cultivo da área no sistema de produção soja e milho.

Tabela 1. Caracterização física e química do Latossolo Vermelho-Amarelo.

\begin{tabular}{cccccccccc}
\hline $\begin{array}{c}\text { Perfil } \\
\text { solo }\end{array}$ & Areia & Silte & Argila & $\mathrm{pH}$ & $\mathrm{P}^{1}$ & $\mathrm{~K}$ & $\mathrm{Ca}$ & $\mathrm{Mg}$ & $\mathrm{H}+\mathrm{Al}$ \\
\hline$--\mathrm{cm}--$ & $--------\mathrm{g} \cdot \mathrm{dm}^{-3}$ & ------- & $\mathrm{CaCl}_{2}$ & $\mathrm{mg} \cdot \mathrm{dm}^{-3}$ & ------ & $\mathrm{cmolc}^{\prime} \mathrm{dm}^{-3}$----- \\
\hline $0,0-20$ & 495 & 100 & 405 & 4,4 & 9,8 & 40 & 1,4 & 0,5 & 7,5 \\
$0,0-2,5$ & - & - & - & 4,7 & 11,5 & 65 & 2,2 & 0,7 & 7,6 \\
$2,5-5,0$ & - & - & - & 4,8 & 10,1 & 44 & 1,7 & 0,5 & 7,1 \\
$5,0-7,5$ & - & - & - & 4,8 & 10,2 & 33 & 1,1 & 0,4 & 6,5 \\
$7,5-10$ & - & - & - & 4,3 & 9,6 & 37 & 0,7 & 0,3 & 6,8 \\
$10-15$ & - & - & - & 4,1 & 8,6 & 29 & 0,3 & 0,1 & 7,1 \\
$15-20$ & - & - & - & 4,2 & 7,1 & 27 & 0,4 & 0,2 & 6,9 \\
\hline
\end{tabular}

No preparo inicial do solo realizou duas gradagens seqüenciais, sendo as grades equipadas com discos de cortes recortados de 32 polegadas. Em seguida foi feita correção da acidez do solo com uso de $3.500 \mathrm{Kg}^{\cdot} \mathrm{ha}^{-1}$ de calcário dolomítico (PRNT de $70 \%$ ), com $30 \% \mathrm{CaO}$ e $16 \% \mathrm{MgO}$. Após a aplicação foi efetuada uma gradagem leve para incorporação do corretivo.

$\mathrm{O}$ delineamento experimental foi em blocos casualizados em esquema fatorial 6x6 (modos de 
adubação fosfatada $\mathrm{x}$ profundidade) em quatro repetições. As parcelas consistiam de 10 metros de comprimento e 3 metros de largura, totalizando uma área de $30 \mathrm{~m}^{2}$, a área útil foi de $5,4 \mathrm{~m}^{2}$ por parcela.
Os tratamentos consistiam na combinação da aplicação do P a lanço sem incorporação e em linha de plantio antes da semeadura da soja (Tabela 2).

Tabela 2: Descrição dos tratamentos.

\begin{tabular}{cc}
\hline Tratamentos & Descrição \\
\hline 1 & Testemunha \\
2 & $100 \%$ Lanço \\
3 & $75 \%$ Lanço e 25 Linha \\
4 & $50 \%$ Lanço e 50\% Linha \\
5 & $25 \%$ Lanço e $75 \%$ Linha \\
6 & $100 \%$ Linha \\
\hline
\end{tabular}

A dose padrão utilizada em todos os tratamentos consistiu de $120 \mathrm{~kg} \mathrm{ha}^{-1}$ de $\mathrm{P}_{2} 0_{5}$, na forma de Fosfato Monoamônico (MAP), variando apenas, as proporções na forma a lanço e em linha. $\mathrm{O}$ fertilizante foi pesado e acondicionado em sacos plásticos com a quantidade a ser distribuída manualmente em cada linha de plantio, assim como a quantidade a ser distribuída á lanço.

Os sulcos de plantio foram abertos com auxílio de uma adubadora-semeadora para aplicação dos tratamentos que preditavam da adubação em linha de plantio. Em seguida os sulcos foram fechados para aplicação dos tratamentos envolvendo adubação a lanço.

A semeadura da soja, cultivar Anta 82 RR foi realizada em densidade de 555.000 sementes por hectare, sendo os tratos culturais mantidos de forma comum á todos os tratamentos. Para o cultivo sucessivo de milho safrinha, utilizou-se o híbrido AG 7000 PRO, semeado na densidade de 55.000 sementes por hectare. Sendo as exigências nutricionais supridas para melhor expressão do potencial genético deste material, porém mantidos os tratamentos com fósforo (MAP) implantados na safra.

A colheita da soja foi realizada manualmente perfazendo uma área útil de $5,4 \mathrm{~m}^{2}$ por parcela. $\mathrm{O}$ material colhido foi trilhado $\mathrm{e}$ peneirado, sendo os resíduos vegetais picados e devolvidos a cada unidade experimental, em seguida, fez a medição da umidade e do peso dos grãos, para obtenção da produtividade líquida (Kg $\left.\mathrm{ha}^{-1}\right)$.

A altura média das plantas de soja foi determinada escolhendo aleatoriamente 20 plantas dentro de cada parcela.

A segunda safra de verão (milho safrinha) foi avaliada perante os parâmetros de altura média de plantas (15 plantas ao acaso por parcela) e produtividade média de grãos $\left(\mathrm{Kg} \cdot \mathrm{ha}^{-1}\right)$.
As amostras de solo foram coletadas após o cultivo da segunda safra (milho safrinha), nas profundidades 0 - 2,5; 2,5 - 5,0; 5,0 - 7,5; 7,5 - 10; 10 - 15 e 15 - $20 \mathrm{~cm}$, de forma manual com o auxílio de espátulas e réguas, sendo os pontos de coleta localizados transversalmente a linha de plantio, iniciando na entre linha, passando pela linha de plantio e indo até o meio da próxima entre linha. Os teores de $\mathrm{P}$ disponível no solo foram extraídos pelo método da Resina de Troca Aniônica (RAIJ et al., 1986). A partir disso, submetidos ao teste F, empregando a análise de variância para blocos ao acaso, em esquema de parcela subdividida, onde foi considerado como parcela os tratamentos e subparcela as seis profundidades amostradas.

Para análise foliar de $\mathrm{P}$, foram coletadas 15 folhas de soja (terceira folha com pecíolo com base no ápice das plantas) em pleno florescimento, conforme metodologia descrita por Malavolta (1992). O teor de $\mathrm{P}$ foi determinado por meio da digestão nítrico-perclórica (MALAVOLTA et al. 1997).

A análise estatística aplicada aos dados de altura de plantas e produtividade de ambas as culturas, teores de $\mathrm{P}$ nas folhas de soja e teores de $\mathrm{P}$ no solo foram submetidas a análise de variância (Teste de F; p<0,05) e comparação de médias pelo teste de Tukey a 5\% de significância (FERREIRA, 2008).

\section{RESULTADOS E DISCUSSÃO}

\section{Fósforo no solo}

Todos os tratamentos apresentaram uma diminuição acentuada (estratificação) no teor de $\mathrm{P}$ com o aumento da profundidade, independente da combinação dos modos de aplicação empregados (Figura 01). Resultados semelhantes foram obtidos por Costa (2009) e Santos (2009).

A estratificação do $\mathrm{P}$ ao longo do perfil do solo pode ser influenciada ao longo do tempo pelos 
modos de adubação, seja superficial na linha de plantio ou a lanço em área total, de certa forma, acarretará num gradiente de $\mathrm{P}$ (HOWARD et al. 1998). Visando diminuir o efeito da estratificação do $\mathrm{P}$ no perfil de solo, pode utilizar espécies com sistemas radiculares mais densos e agressivos, uma vez que sua posterior decomposição fornecerá $\mathrm{P}$ em maiores profundidades aos vegetais (GREGORY, 2006).

O teor de $\mathrm{P}$ na camada superficial do solo mostrou grandes variações no comportamento deste elemento perante os modos de aplicação para a profundidade de $0,0-2,5 \mathrm{~cm}$, onde a testemunha apresentou o menor teor $\left(11,50 \mathrm{mg} \cdot \mathrm{dm}^{-3}\right)$, no entanto, onde $100 \%$ e $75 \%$ da dose de fósforo foi aplicado a lanço foram encontrados os maiores níveis, 54,14 e $52,05 \mathrm{mg} \cdot \mathrm{dm}^{-3}$ respectivamente (Tabela 03).

$\mathrm{Na}$ profundidade de $2,5-5,0 \mathrm{~cm}$ ocorreu menor variação entre os tratamentos, independente da forma de como se combinou os modos de aplicação (Tabelas 3). Onde $25 \%$ e $50 \%$ da dose de $\mathrm{P}$ foram aplicados nas linhas de plantio os resultados foram superiores, diferindo dos demais.

Tabela 3. Teor de $\mathrm{P}\left(\mathrm{mg} \cdot \mathrm{dm}^{-3}\right)$ entre as profundidades avaliadas em relação as combinações dos modos de aplicação (Extrator Resina).

\begin{tabular}{|c|c|c|c|c|c|c|}
\hline \multirow{2}{*}{ Trat $^{1}$} & \multicolumn{6}{|c|}{ Profundidades $(\mathrm{cm})$} \\
\hline & $0-2,5$ & $2,5-5$ & $5-7,5$ & $7,5-10$ & $10-15$ & $15-20$ \\
\hline T $01^{2}$ & $11,50 \mathrm{e}^{1} \mathrm{~A}^{2}$ & $9,89 \mathrm{dAB}$ & $10,17 \mathrm{bAB}$ & $9,60 \mathrm{bAB}$ & $8,60 \mathrm{abBC}$ & $7,03 \mathrm{abC}$ \\
\hline $\mathrm{T} 02^{3}$ & $54,14 \mathrm{aA}$ & $18,90 \mathrm{cB}$ & $14,08 \mathrm{aC}$ & $10,77 \mathrm{bD}$ & $8,42 \mathrm{abE}$ & $7,08 \mathrm{abE}$ \\
\hline $\mathrm{T} 03^{4}$ & $52,05 \mathrm{aA}$ & $30,51 \mathrm{aB}$ & $11,25 \mathrm{bC}$ & 9,94 bC & 7,69 bD & $5,69 \mathrm{bD}$ \\
\hline T $04^{5}$ & $27,07 \mathrm{cA}$ & $28,76 \mathrm{aA}$ & $15,25 \mathrm{aB}$ & $10,94 \mathrm{abC}$ & $7,65 \mathrm{bD}$ & $5,56 \mathrm{bD}$ \\
\hline $\mathrm{T} 05^{6}$ & $38,80 \mathrm{bA}$ & $21,37 \mathrm{bB}$ & $13,86 \mathrm{aC}$ & $12,95 \mathrm{aC}$ & $10,27 \mathrm{aD}$ & $8,95 \mathrm{aD}$ \\
\hline T $06^{7}$ & $19,89 \mathrm{dA}$ & $20,59 \mathrm{bcA}$ & $13,94 \mathrm{aB}$ & $10,64 \mathrm{bC}$ & 9,38 abCD & $8,03 \mathrm{aD}$ \\
\hline
\end{tabular}

Médias seguidas por letras distintas, minúscula na coluna e maiúscula na linha, diferem entre si pelo teste de tukey (P<0,05). $\mathrm{CV}: 6,55$ \% e DMS (5\%): 2,12 para coluna e CV: 6,55 \% e DMS (5\%): 2,126 para linha; ${ }^{1}$ Tratamento; ${ }^{2}$ Testemunha; ${ }^{3} 100 \%$ lanço; ${ }^{4} 75 \%$ lanço e $25 \%$ linha; ${ }^{5} 50 \%$ lanço e $50 \%$ linha; ${ }^{6} 25 \%$ lanço e $75 \%$ linha; ${ }^{7} 100 \%$ linha

$\mathrm{Na}$ profundidade de 5,0 - 7,5 $\mathrm{cm}$ houve superioridade das combinações de adubação com 100, 75 e $50 \%$ da dose de P aplicados na linha de plantio e $100 \%$ da dose de $\mathrm{P}$ aplicado a lanço, em relação ao modo de adubação com $25 \%$ de $\mathrm{P}$ na linha de plantio e a testemunha (Tabelas 03 ). O fato do tratamento com $100 \%$ da dose de $\mathrm{P}$ aplicado a lanço estar entre os tratamentos superiores, é visto com certa incoerência, uma vez que nesta profundidade $(5,0-7,5 \mathrm{~cm})$ não se espera efeito deste modo de adubação, isto, por consequência do $\mathrm{P}$ apresentar baixa mobilidade no solo (BARBER, 1984) e baixa disponibilidade nos solos oxídicos (NOVAIS et al. 2007).

Ocorreu inversão na superioridade das combinações de adubação com o aumento da profundidade amostrada, ou seja, na profundidade de $0,0-2,5 \mathrm{~cm}$ foram superiores os tratamentos com maior parte da adubação a lanço, entretanto na profundidade de $5,0-7,5 \mathrm{~cm}$ foram superiores os tratamentos com maior parte da adubação em linha de plantio. O motivo para esta inversão esta ligado ao local de aplicação do $\mathrm{P}$, uma vez que na implantação do experimento as porções de $\mathrm{P}$ aplicadas na linha de plantio foram depositados abaixo das sementes, em uma profundidade média de $6 \mathrm{~cm}$ e o $\mathrm{P}$ aplicado a lanço se concentrou na superfície do solo.

Abaixo de $10 \mathrm{~cm}$ de profundidade, todas as combinações de adubação fosfatada apresentaram comportamentos similares, demonstrando diminuição no teor de $\mathrm{P}$ (Figura 1). As profundidades $10-15$ e 15 a $20 \mathrm{~cm}$ (Tabela 3) revelaram pouca diferença entre os tratamentos, o que de certa forma indica uma pequena influência da combinação dos modos de aplicação de $\mathrm{P}$ em profundidades superiores a $10 \mathrm{~cm}$. Costa (2008) observou efeito somente até $15 \mathrm{~cm}$ dos modos de aplicação a lanço, linha e em faixa, na distribuição do $\mathrm{P}$ no perfil do solo.

A testemunha não apresentou diferença em relação aos teores de $\mathrm{P}$ com o aumento da profundidade. Tendo em vista que não houve aplicação de $\mathrm{P}$.

Os tratamentos com 100 e $75 \%$ da dose de $\mathrm{P}$ aplicados a lanço apresentaram diferenças no teor de $\mathrm{P}$ no solo com o aumento da profundidade. Os teores de $\mathrm{P}$ nas profundidades de $0,0-2,5 ; 2,5-5,0 \mathrm{e}$ $5,0-7,5 \mathrm{~cm}$ diferiram estatisticamente entre si. Beck e Sanchez (1996) também observaram aumento significativo no teor de $\mathrm{P}$ abaixo da camada em que o nutriente foi aplicado. 


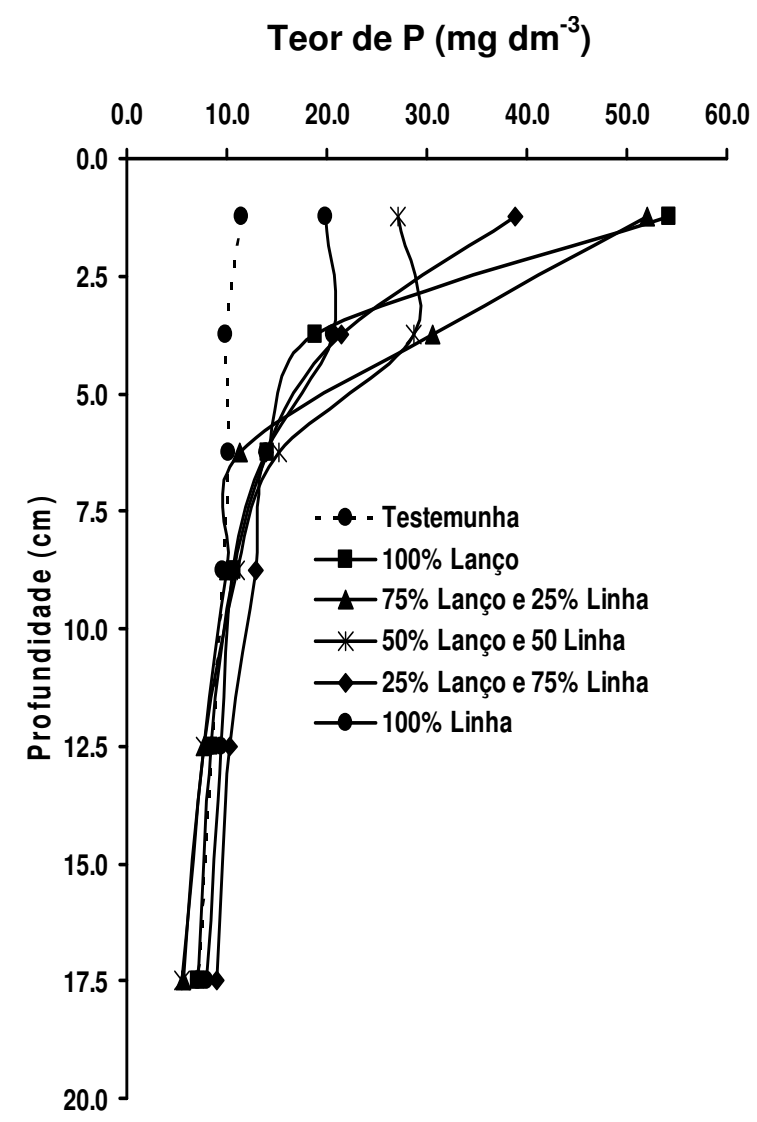

Figura 01. Distribuição do P no solo em função da profundidade e dos tratamentos. (Extrator Resina).

Até a profundidade de $5,0 \mathrm{~cm}$, a combinação de $50 \%$ da dose de P aplicado a lanço e $50 \%$ em linha de plantio, apresentou alto teor de $\mathrm{P}$ no solo (entre 27,07 e $28,76 \mathrm{mg} \cdot \mathrm{dm}^{-3}$ ), estando de acordo com as recomendações para culturas anuais em sequeiro (SOUSA et al. 2004). As profundidades 0,0-2,5 e 2,5-5,0 cm não apresentaram diferença estatística, mostrando que a aplicação combinada de $\mathrm{P}$ a lanço e na linha de plantio contribuiu para a homogeneização do teor de $\mathrm{P}$ na profundidade de $0,0-5,0 \mathrm{~cm}$, quando comparados aos tratamentos com maior parte da dose de $\mathrm{P}$ aplicados a lanço.

As combinações com maiores percentuais de adubação a lanço (100 e 75\%) mostraram que o P permaneceu na superfície do solo $(0,0-2,5 \mathrm{~cm})$. Tal relato corrobora com outros resultados na literatura que evidenciam teores de P na camada de 0,0 - 2,5 $\mathrm{cm}$ de três vezes (DUIKER; BEEGLE 2006) a dez vezes (BAYER; BERTOL 1999) maiores em sistemas que priorizam a aplicação a lanço do fertilizante fosfatado, como, o sistema de produção em plantio direto, enfatizando assim, a tendência destes modos de aplicação em acumular $\mathrm{P}$ em superfície. Porém o $\mathrm{P}$ localizado em maior proporção nesta região pode representar algumas desvantagens, tais como a perda por erosão (ANDRASKI et al. 2003), menor disponibilidade de nutrientes em veranicos (NOVAIS; SMYTH 1999) e também ocasionar uma concentração superficial de raízes, tornando a planta mais susceptível a períodos de déficit hídrico (KLEPKER. 1991).

\section{Parâmetros biométricos e composição mineral}

A produtividade média de grãos de soja diferiu entre os distintos modos de aplicação de $\mathrm{P}$, tendo valores superiores $\left(2887,9 \mathrm{Kg} \cdot \mathrm{ha}^{-1}\right)$, intermediários $\left(2107,6\right.$ a $\left.2610,8 \mathrm{~kg} \cdot \mathrm{ha}^{-1}\right)$ e inferiores $\left(<2107,6 \mathrm{~kg} \cdot \mathrm{ha}^{-1}\right)$. A testemunha foi o tratamento que apresentou menor rendimento de grãos, uma vez que não houve aplicação de $\mathrm{P}$ e o solo apresentava baixa fertilidade natural (Tabela 4).

A maior produtividade $\left(2887,9 \mathrm{Kg} \cdot \mathrm{ha}^{-1}\right)$ ocorreu quando $100 \%$ da dose de $\mathrm{P}$ foi aplicado em linha de plantio. Nas produtividades intermediarias $\left(2107,6\right.$ a $\left.2610,8 \mathrm{~kg} \cdot \mathrm{ha}^{-1}\right)$ os tratamentos que receberam parte da combinação da adubação a lanço, desde $25 \%$ até $100 \%$, não foi observada diferença estatística. Este resultado mostrou-se 
inovador neste estudo, tendo em vista que dentro da grande faixa (25 a 100\% da adubação a lanço), pode definir aplicações sem que haja perda de produtividade.

A altura média das plantas de soja nos tratamentos que predicavam combinações com $100 \%, 75 \%$ e $50 \%$ da dose de P aplicado em linha de plantio foram superiores aos demais, evidenciando de certa forma, a importância da melhor localização do $\mathrm{P}$ para o crescimento dos vegetais. Além da testemunha, os tratamentos com 100 e $75 \%$ da dose de $\mathrm{P}$ aplicados a lanço obtiveram resultados inferiores (Tabela 4 ). A testemunha por não ter recebido $\mathrm{P}$, apresentou a menor altura $(34,8$ $\mathrm{cm})$. O fato do tratamento com $100 \%$ da dose de $\mathrm{P}$ aplicado a lanço não ter sido diferente da testemunha na altura média das plantas, pode estar relacionado à baixa mobilidade do $\mathrm{P}$ no solo (NOVAIS et al. 2007), isso fez com que este elemento se concentrasse na superfície do solo, limitando a capacidade das raízes no processo de absorção em maiores profundidades.

De acordo com adaptação feita por Sousa e Lobato (2004), os teores adequados de P em folhas de soja estão entre 2,5 e $5,0 \mathrm{~g} \cdot \mathrm{kg}^{-1}$ de matéria seca. No entanto, os tratamentos com 50 e $75 \%$ da dose de $\mathrm{P}$ aplicados em linha de plantio encontram-se no limiar deste intervalo, os demais estão com teores abaixo dos mínimos definidos. A associação da adubação em $75 \%$ a lanço e $25 \%$ em linha de plantio, mostrou insuficiência para suprir toda necessidade das plantas pelo $\mathrm{P}$ (Tabela 4).

Tabela 4. Valores médios de altura de plantas, produtividade e teor de fósforo em plantas de soja.

\begin{tabular}{cccc}
\hline Tratamentos & $\begin{array}{c}\text { Altura de Plantas } \\
(\mathrm{cm})\end{array}$ & $\begin{array}{c}\text { Produtividade } \\
\left(\mathrm{Kg} \mathrm{ha}^{-1}\right)\end{array}$ & $\begin{array}{c}\text { Teor de P na folha } \\
\left(\mathrm{g} \mathrm{kg}^{-1}\right)\end{array}$ \\
\hline $\mathrm{T}^{1}$ & $34,8 \mathrm{~d}$ & $1434,9 \mathrm{c}$ & $1,7 \mathrm{c}$ \\
$\mathrm{T}^{2}$ & $38,0 \mathrm{~cd}$ & $2107,6 \mathrm{~b}$ & $2,4 \mathrm{ab}$ \\
$\mathrm{T}^{3}$ & $41,5 \mathrm{bcd}$ & $2188,5 \mathrm{~b}$ & $1,8 \mathrm{bc}$ \\
$\mathrm{T}^{4}$ & $44,8 \mathrm{abc}$ & $2395,0 \mathrm{ab}$ & $2,5 \mathrm{a}$ \\
$\mathrm{T}^{5}$ & $47,7 \mathrm{ab}$ & $2610,8 \mathrm{ab}$ & $2,5 \mathrm{a}$ \\
$\mathrm{T}^{6}$ & $50,1 \mathrm{a}$ & $2887,9 \mathrm{a}$ & $2,0 \mathrm{abc}$ \\
\hline Média & 42,82 & 2270,8 & 2,2 \\
DMS & 8,5 & 560,1 & 0,6 \\
\hline
\end{tabular}

Médias seguidas por letras distintas na coluna diferem entre si pelo teste de tukey $(\mathrm{P}<0.05) .{ }^{1}$ Testemunha; ${ }^{2} 100 \%$ lanço; ${ }^{3} 75 \%$ lanço e $25 \%$ linha; ${ }^{4} 50 \%$ lanço e $50 \%$ linha; ${ }^{5} 25 \%$ lanço e $75 \%$ linha; ${ }^{6} 100 \%$ linha;

Os teores foliares de $\mathrm{P}$ nos tratamentos com doses de 100 e $25 \%$ da dose de $\mathrm{P}$ em linha de plantio, juntamente com a testemunha obtiveram os piores resultados. $\mathrm{O}$ baixo teor de $\mathrm{P}$ encontrado nas folhas de soja, justamente onde $100 \%$ da dose de $\mathrm{P}$ foi aplicada em linha, pode ser explicado pelo fato, desse modo de aplicação ter proporcionado maior rendimento de grãos, exigindo maior translocação, deste nutriente, das folhas para os grãos.

A produtividade, altura média de plantas e teor de $\mathrm{P}$ na folha de soja evidenciam uma superioridade das combinações da adubação onde 50,75 e $100 \%$ da dose de P foi aplicado em linha de plantio. Afirmando que a eficiência da aplicação de $\mathrm{P}$ a lanço em relação à aplicação em linha de plantio pode estar associada ao teor inicial deste nutriente no solo, com isso, quanto maior é a deficiência de $\mathrm{P}$ no solo, maior será a eficiência em rendimento de grãos a aplicação localizada (WELCH et al. 1966) e Costa (2008).

Tabela 05. Valores médios de produtividade e altura de plantas do milho safrinha.

\begin{tabular}{ccc}
\hline Tratamentos & Altura de Plantas $(\mathrm{cm})$ & ${\text { Produtividade }\left(\mathrm{Kg} \mathrm{ha}^{-1}\right)}^{\mathrm{T}^{1}}$ \\
\hline T2 $^{2}$ & $175,50 \mathrm{~b}$ & $2806,25 \mathrm{~b}$ \\
$\mathrm{~T}^{3}$ & $209,03 \mathrm{a}$ & $5040,88 \mathrm{a}$ \\
T4 $^{4}$ & $207,43 \mathrm{a}$ & $5369,01 \mathrm{a}$ \\
T5 $^{5}$ & $210,10 \mathrm{a}$ & $5160,13 \mathrm{a}$ \\
T6 $^{6}$ & $218,29 \mathrm{a}$ & $4856,25 \mathrm{a}$ \\
Média & $212,57 \mathrm{a}$ & $5163,02 \mathrm{a}$ \\
DMS & 205,49 & 4730,92 \\
\hline
\end{tabular}

Médias seguidas por letras distintas na coluna diferem entre si pelo teste de tukey $(\mathrm{P}<0.05) .{ }^{1}$ Testemunha; ${ }^{2} 100 \%$ lanço; ${ }^{3} 75 \%$ lanço e $25 \%$ linha; ${ }^{4} 50 \%$ lanço e $50 \%$ linha; ${ }^{5} 25 \%$ lanço e $75 \%$ linha; ${ }^{6} 100 \%$ linha; 
A produtividade média dos grãos de milho safrinha não foi afetada pelas combinações dos modos de aplicação de P (Tabela 05). Model e Anghinoni (1992) obtiveram resultados similares trabalhando com resposta de milho a modos de aplicação de adubos fosfatados e tipos de preparo de solo demonstrando que não houve diferença no rendimento do milho. No entanto, Howard et al. (2002) trabalhando com dois sistemas de manejo de solo, ao relacionar o aumento da proporção de $\mathrm{P}$ aplicado a lanço, observou incremento no rendimento de grãos de milho.

A altura média das plantas de milho não diferiram em relação as combinações dos modos de aplicação de $\mathrm{P}$ no solo. Sendo a testemunha o pior tratamento (Tabela 05).

\section{CONCLUSÕES}

A associação da adubação em $75 \%$ a lanço e $25 \%$ na linha, mostrou insuficiência para suprir toda necessidade das plantas de soja pelo fósforo.

A maior produtividade de grãos e altura de plantas de soja, foram obtidos com $100 \%$ da dose de fósforo em linha.

Quando o fertilizante foi aplicado em maior percentual a lanço em área total proporcionou maior acúmulo de fósforo na profundidade de $0,0-2,5 \mathrm{~cm}$. Entretanto, quando houve predomínio da aplicação na linha os maiores acúmulos ocorreram na profundidade de 5,0-7,5 cm.

\begin{abstract}
The need for more studies on the dynamics of fertilization and efficient use of phosphorus in agriculture in the Brazilian cerrado, was purpose for this study, whose aim was to verify the efficiency of the combination of modes of application of phosphate fertilizers in vertical distribution in the soil. The experiment was conducted in southwestern Goiás, in system of production of soybeans and corn. The experimental design was randomized blocks , factorial 6x6 , between modes of fertilization (100\% of broadcast fertilization , $75 \%$ and $25 \%$ in the haul line haul and $50 \%$ to $50 \%$ in line, $25 \%$ haul and $75 \%$ on line, $100 \%$ in line and control) and depths $0,0-2,5 ; 2.5-5.0 ; 5.0-7.5 ; 7.5$ to $10.0 ; 10.0-15.015 .0$ to $20.0 \mathrm{~cm}$. We used a standard dose of $120 \mathrm{~kg} \mathrm{ha}^{-1}$ of $\mathrm{P}_{2} \mathrm{O}_{5}$ as Monoammonium Phosphate (MAP). Evaluations were $\mathrm{P}$ content in the soil at depths 0,0 to 2,$5 ; 2,5$ to 5,$0 ; 5,0$ to 7,$5 ; 7,5$ to 10,$0 ; 10,0$ to 15,$0 ; 15,0$ to $20,0 \mathrm{~cm}$. Foliar P concentration, height and productivity of soybean plants, and height and productivity of corn second crop. The association of fertilizer by $75 \%$ broadcast and $25 \%$ line, proved insufficient to meet all needs of the plants by phosphorus. When the fertilizer was applied at a higher percentage broadcasted in total provided greater accumulation of phosphorus in the layer 0,0 to $2,5 \mathrm{~cm}$, however, when there was a predominance of the application within the row the highest accumulations occurred in layer 5,0 to $7,5 \mathrm{~cm}$.
\end{abstract}

KEYWORDS: Fertilization broadcast. Brazilian savannah. Glycine max. Line of planting. Zea mays.

\title{
REFERÊNCIAS
}

ANDRASKI, T. W.; BUNDY, L. G.; KILIAN, K. C. Manure history and long-term effects on soil properties and phosphorus losses in runoff. Journal of environmental quality, Madison, v. 32, p. 1782-1789, 2003.

ANGHINONI, I. Uso de fósforo pelo milho afetado pela fração de solo fertilizada com fosfato solúvel. Revista Brasileira de Ciência do Solo, Viçosa, v. 16, p. 349-353, 1992.

ANGHINONI, I.; BARBER, S. A. Phosphorus application rate and distribution in the soil and phosphorus uptake by corn. Soil Science Society of America Journal, Madison, v. 44, p. 1041-1044, 1980.

BAYER, C.; BERTOL, I. Características químicas de um Cambissolo húmico afetadas por sistemas de preparo com ênfase na matéria orgânica. Revista Brasileira de Ciência do Solo, Viçosa, v. 23, p. 867-694, 1999.

BARBER, S. A. Soil nutrient bioavailability: A mechanistic approach. New York, JonhWiley and Sons, 1984, 398p.

BECK, M. A.; SANCHEZ, P. A. Soil phosphorus movement and budget after 13 years of fertilized cultivation in the Amazon basin. Plant and Soil, v. 184, p. 23-31, 1996. http://dx.doi.org/10.1007/BF00029271

BLEVINS, D. G. Why plants need phosphorus. Better Crops, Norcross, Georgia, v. 83, n. 2, p. 29-30, 1999. 
BORDOLI, J. M.; MALLARINO, A. P. Deep and shallow banding of phosphorus and potassium as alternatives to broadcast fertilization for no-till corn. Agronomy Journal, Madison, v. 90, p. 27-33, 1998.

http://dx.doi.org/10.2134/agronj1998.00021962009000010006x

COSTA, S. E. V. G. de A. Distribuição de fósforo, de potássio e de raízes e rendimento de milho em sistemas de manejo de solo e da adubação em longo prazo. Dissertação de Mestrado em Ciência do Solo, Universidade Federal do Rio Grande do Sul, Porto Alegre, 106p, 2008.

COSTA, S. E. V. G. de A. Phosphorus and root distribution and corn growth as related to long-term tillage systems and fertilizer placement. Revista Brasileira de Ciência do Solo, Viçosa, v. 33, n. 5, p. 1237-1247, 2009.

DUIKER, S. W.; BEEGLE, D. B. Soil fertility distributions in long-term no-till, chisel/disk and moldboard plow/disk systems. Soil \& Tillage Research, Amsterdam, v. 88, p. 30-41, 2006.

http://dx.doi.org/10.1016/j.still.2005.04.004

Empresa Brasileira de Pesquisa Agropecuária (EMBRAPA). Sistema Brasileiro de Classificação de Solos. $2^{\mathrm{a}}$ ed. Rio de Janeiro, Embrapa. 412p, 2006.

FERREIRA, D. F. SISVAR: Um programa para análises e ensino de estatística. Revista Symposium, Campinas, v. 6, p. 36- 41, 2008.

FOX, R. L.; KANG, B. T. Influence of phosphorus fertilizer placement and fertilization rate on maiz nutrition. Soil Science, Baltimore, v. 125, p. 34-40, 1978. http://dx.doi.org/10.1097/00010694-197801000-00006

GREGORY, P. Plant roots-growth, activity and interaction with soils. Oxford: lackwell Publishing, 318p. 2006.

HOWARD, D. D.; ESSINGTON, M. E.; LOGAN, J. Long-term broadcast and banded phosphorus fertilization of corn produced using two tillage systems. Agronomy Journal, v. 94, p. 51-56, 2002.

http://dx.doi.org/10.2134/agronj2002.0051

HOWARD, D. D.; MULLEN, M. D.; ESSINGTON, M. E. Assessing nutrients stratification within a long-term no-tillage corn soil. Annual Southern Conservation Tillage Conference for Sustainable Agriculture, v. 21, Arkansas. Proceedings... Arkansas agriculture experiment station, 1998.

KLEPKER, D.; Nutrientes e raízes no perfil e crescimento de milho e aveia em função do preparo do solo e modos de adubação. 1991. 117 p. Dissertação (Mestrado) - Programa de Pós-Graduação em Ciência do Solo, Faculdade de Agronomia, Universidade Federal do Rio Grande do Sul, Porto Alegre, 1991.

MALAVOLTA, E. ABC da análise de solo e folhas: amostragem, interpretação e sugestões de adubação. São Paulo: Ceres, 1992.

MALAVOLTA, E.; VITTI, G. C.; OLIVEIRA, S. A. Avaliação do estado nutricional das plantas. 2.ed. Piracicaba: Potafos, 319p, 1997.

MARSCHNER, H.; Mineral nutrition of higher plants. London: Academic Press, 1995. 889p.

MODEL, N. S.; ANGHINONI, I. Respostas do milho a modos e técnicas de preparo do solo. Revista Brasileira de Ciência do Solo, Viçosa, v. 16, p. 55-59, 1992.

MOTOMIYA, W. R.; FABRICIO, A. C.; MARCHETTI, M. E.; GONÇALVES, M. C.; ROBAINA, A. D.; NOVELINO, J. O. Métodos de aplicação de fosfato na soja em plantio direto. Pesquisa Agropecuária Brasileira. Brasília, v. 39, n. 4, p. 307-312, 2004. 
NOVAIS, R. F.; SMYTH, T. J. Fósforo em solo e planta em condições tropicais. Viçosa: UFV, 1999. 399p.

NOVAIS, R. F.; ALVAREZ V., V. H.; BARROS, N. F.; FONTES, R. L. F.; CANTARUTTI, R. B.; NEVES, J. C. L. Fertilidade do solo. Sociedade Brasileira de Ciência do Solo, p. 471-537. 2007.

NUNES, R. S; SOUSA, D. M. G; GOEDERT, W. J; VIVALDI, L. J. Distribuição de fósforo no solo em razão do sistema de cultivo e manejo da adubação fosfatada. Revista Brasileira de Ciência do Solo, Viçosa, v. 35, p. 877-888, 2011.

PAVINATO, P. S.; CERETTA, C. A. Fósforo e potássio na sucessão trigo/milho: épocas e formas de aplicação. Ciência Rural, Santa Maria, v. 34, n. 6, p. 1779-1784, 2004. http://dx.doi.org/10.1590/S010384782004000600017

POTTKER, D. Aplicação de fósforo no sistema plantio direto. Embrapa Trigo, Boletim de Pesquisa, v.2. Passo Fundo: Embrapa, 1999. 32p.

RANDALL, G. W.; HOEFT, R. G. Placement methods for improved efficiency of P and K fertilizers: A review. Journal of Production in Agriculture, Madison, v. 1, p. 70-79, 1988. http://dx.doi.org/10.2134/jpa1988.0070

RAIJ, B. van; QUAGGIO, J. A.; SILVA, N. M. da. Extraction of phosphorus, potassium, calcium, and magnesium from soils by an ion-exchange resin procedure. Communications in Soil Science and Plant Analysis, New York, v. 17, n. 5, p. 547-566, 1986. http://dx.doi.org/10.1080/00103628609367733

SANTOS, D. B. M. Distribuição do fósforo no perfil do solo sob sistema plantio direto. Dissertação de Mestrado, Faculdade de Agronomia e Medicina Veterinária, Universidade de Brasília, 81p, 2009.

SEGATELLI, C. R. Produtividade da soja em semeadura direta com antecipação da adubação fosfatada e potássica na cultura da Euleunice coracana. 2004. Dissertação de Mestrado, Universidade de São Paulo, Piracicaba. 115p. 2004.

SOUSA, D. M. G. de; LOBATO, E. Cerrado: correção do solo e adubação. Embrapa Informação Tecnológica, Brasília, 2004. 416p.

SOUSA, D. M. G.; LOBATO, E.; REIN, T. A. Adubação com fósforo. In: SOUSA, D.M.G.; LOBATO, E. Cerrado: Correção do solo e adubação. Planaltina, Embrapa Cerrados, p. 147-168, 2004.

STAUFFER, M.D.; SULEWSKI, G. Phosphorus: essential for life. In: SIMPÓSIO SOBRE FÓSFORO NA AGRICULTURA BRASILEIRA, 2003, Piracicaba. Anais. Piracicaba: Potafos/Anda, 2003. 1 CD-ROM.

WELCH, L. F.; MULVANEY, D. L.; BOONE, L. V.; MCKIBBEN, G. E.; PENDLETON, J. W. Relative efficiency of broadcast versus banded phosphorus for corn. Agronomy Journal, v. 58, p. 283-287, 1966. http://dx.doi.org/10.2134/agronj1966.00021962005800060020x 